\title{
Upstream Causes of the COVID-19 Pandemic: A Need for Public Education
}

\author{
Author Details
Al Lauzon*
School of Environmental Design and Rural Development, University of Guelph, Canada
*Corresponding author
Al Lauzon, School of Environmental Design and Rural Development, University of Guelph, Canada \\ Article History \\ Received: February 28, 2021 Accepted: March 01, 2021 Published: March 01, 2021
}

\begin{abstract}
The last year we have seen COVID-19 spread across the globe with unprecedented deaths and illness while racking havoc on the global economy. People are eager to return to normal and are optimistic that vaccines are now rolling out. However, it must be understood that the conditions that are responsible for zoonosis pandemics are a product of the development of industrial agriculture and until we change how we produce food, we are likely to continue to experience pandemics more frequently. There is a need for education of the public and politicians that we must do more than deal with this pandemic, we must actively work toward changing global food production systems.
\end{abstract}

\section{Opinion}

As I write this article, we have now been dealing with the COVID-19 pandemic for well over a year and there have been over 111 million cases of COVID-19 resulting in almost 2.5 million deaths. While the health impact has been unimaginable, the economic impact has also been devastating and it will be some time before we fully understand the consequences; we could be years in recovery, if we ever recover.

It has been found that since the beginning of the COVID-19 pandemic we have seen significant levels of psychological stress that would meet the criteria for clinical relevance [1]. Specifically, it has been reported that we are seeing increasing rates of depression, anxiety and Post Traumatic Stress Disease [2]. One can only wonder what the long-term consequences of these mental health afflictions will be. Those who were already suffering poor mental health may see these conditions worsen as people suffer the burdens of social isolation, working from home while looking after children, or unemployment and economic loss. Furthermore, job losses are predicted to lead to more suicides [1], predicting that in Canada suicides will rise from 418 to 2114 as a result of COVID-19 [3]. Canada is a relatively small country population wise, and we have no idea of what the total will be globally. Then there is the aftermath, or fallout of having lived through the pandemic. Given what we have learned from previous disasters, I believe the toll on the health and well-being of populations will be significant when we have a moment to breathe, and the consequences may ripple through populations for years to come.
The pandemic has also highlighted socio-economic inequities, often with those who are most socio-economically vulnerable or racial minorities suffering the greatest effects of both the disease and the economic consequences of the disease [4]. This is further exacerbated by increasing food insecurity where there has been a $50 \%$ increase in demand on emergency food services since the beginning of the pandemic [5]. Meanwhile, governments are struggling to meet the needs of individuals and businesses at the same time they are facing a decrease in revenues, while struggling with what measures to take, deciding when is it prudent to re-open or close economies. The stress on politicians a must also be taking a toll as they continue to govern and decide in world of great uncertainty. But for now, most people are tired and there is a strong desire to get back to "normal". The challenge is I do not believe we will or can return to normal, or what we considered normal before the pandemic; perhaps a new normal will emerge.

One of the challenges we face with the general public, and perhaps politicians too, is the idea that this is an acute problem that will disappear as we vaccinate our way out. And while vaccinating the global population is a logistical nightmare, and even if it is accomplished the public must understand that the emergence of COVID-19 is a symptom of a deeper problem-changes in the environment that we have brought about [6,7]. While the pandemic may be considered an "acute condition", there is a deeper "chronic condition" of which the pandemic is merely a manifestation, and much like a chronic disease, its onset is often precipitated by poor choices with regard to how 
one chooses to live. Simply stated, we have made choices that have created environmental conditions that increase the probability of the emergence of zoonoses, something we cannot predict. As has been noted, the transfer of disease from animal to humans is not rocket science and we have had an understanding of how disease transfers from animal to humans for a long-time; this is not new science [6], but the probability of pandemic occurrences is increasing owing to environmental change and greater pressure we are placing on it [8].

While we cannot predict the emergence of zoonoses, we do know one factor that has increased the probability of zoonoses-industrial agriculture, an upstream cause as result of an agriculture dominated by agribusiness corporations [9].

It has been pointed out that of 175 newly emerging or spreading human diseases, 132 are zoonoses [6]. It is further argued that changing patterns of zoonoses is a consequence of complex social and ecological changes that are a result of choices we have made, particularly as they relate to food production. These changes have disturbed ecosystems where animals and microbes had previously lived in harmony. This ecological disturbance puts more wildlife, often the origin of zoonoses, in greater contact with livestock which can be an intermediary in the spread of viruses to human populations or increase direct contact with people. For example, one animal population that increases the risk of zoonoses are bats and altering environmental conditions will often create conditions that accommodate a diverse number of species that would not normally be found together in natural niches, increasing risk to human populations [8]. This is a direct consequence of changing ecosystems through anthropizing environments that increase their attraction to a variety of bat species. The consequence of changing ecosystems is the creation of new patterns of infection [6].

This ecological disturbance is a result of humans' continuous expansion and encroachment on natural areas, often as a result of agricultural expansion [9]. In tandem with the expansion of agricultural lands and larger farms, there is an increasing concentration of ownership and corporatization of agriculture. Fewer farmers in the developing world means eliminating livelihoods and often forcing rural people to migrate to urban shantytowns, creating impoverished communities that are unhygienic and ripe for the spread of infectious disease. In developed economies we see increasing intensification of livestock production where concentration of livestock leads to conditions that not only promote the spread of viral infections, they often inadvertently create the conditions for more virulent strains of the viruses to evolve. Increasing the likelihood of viral infections is a consequence of public policy and social practise; the forms of food production we are increasingly supporting and engaging in shapes viral evolution, undermining the ecological controls that had previously provided control of microbes, increasing human exposure and risk.

The spread of disease is further exacerbated by global trade and travel as we have watched COVID-19 spread across the globe, leaving few people untouched in some way by the pandemic [11]. We need to recognize that it is our industrial system of food production, global trade and travel, and our lifestyles that are creating ideal viral environments [11]. It has been suggested that we need to think about landscapes, ecosystems and how we choose to feed ourselves, and to date the determining factor for food production has been consumer demand for greater varieties of food, more meat, and we want to pay less for it $[6,7]$. Agribusiness is only too willing to comply with our desires as they put profits over environmental concerns and the health and well-being of people. Being a well-connected global conglomerate means never having to say you are sorry for the damage done as you optimize profits and socialize external costs, leaving government to do the cleanup.
I started this essay by stating that for most people and politicians the COVID-19 pandemic is understood as an acute condition. The ongoing rhetoric about getting back to normal is an indicator of this perspective; the pandemic while deadly, has just been an intermittent inconvenience for many people and they yearn to return to normal. Yet it is the choices that we are making with regard to food production and lifestyle that is ultimately escalating risks of pandemics. We need to make choices and recognize that COVID-19 is merely a symptom of a chronic condition that is a consequence of lifestyle and our desire for diverse and cheap foods. There is no escape from nature, it was here before us and will be here when we are gone should we not change our ways. We all share in a common future, and all does not mean just humans, but all forms of life. We need to learn to be respectful of this place we call home and operate within the parameters nature sets. As the epidemiologist David Waltner-Toews tells us, we will either have a common future, or none at all.

There is a general educational need to help people understand that the choices we are making, including the choices we make as consumers, are creating the conditions whereby pandemics will become more frequent. The resolution of this pandemic through vaccination is the equivalent of stopping the bleeding before engaging in the cure. We need to change our ways because this pandemic has taken its toll in terms of human lives, human suffering, and fiscal damage. The reality is we cannot afford another pandemic, our health and economy have "spent" much of their resilience in responding to this one. We need to change our ways. So as we embrace the future we must acknowledge in order to deal with the issue of zoonoses, and ultimately with pandemics, we need to re-think our place in the world, how we understand progress, and we need to re-think how we produce food [7].

\section{References}

1. Xiong J, O Lipsitz, F Nasri, LMW Lui, H Gill, et al., (2020) Impact of COVID-19 pandemic on mental health in the general population: a systematic review. J Affect Disod 277: 55-64.

2. Tusker P, CC Zapla (2021) Post COVID stress disorder: another emerging consequence of the global pandemic. Psychiatric Times 38(1).

3. McIntyre RS, Y Lee (2020) Projected increases in suicides in Canada as a consequence of COVID-19. Psychiatry Res 290, 113104.

4. https://www.mckinsey.com/industries/public-and-social-sector/ourinsights/reimagining-the-postpandemic-economic-future.

5. Wolfson JA, CW Leung (2020) Food insecurity during COVID-19: an acute crisis with long-term implications. Am J Public Health 110(12): 1763-1765.

6. Waltner-Toews D (2007) The Chickens Fight Back: Pandemic Panics and Deadly Diseases that Jump from Animals to Humans. Vancouver, Canada: Greystone Books LTD.

7. Waltner-Toews D (2020) On Pandemics: Deadly Diseases from Bubonic Plague to Coronavirus. Vancouver, Canada: Greystone Books LTD.

8. Afelt A, R Frutos, C Devaux (2018) Bats, coronaviruses, and deforestation: emergence of novel infectious diseases? Front Microbiol, 9: 702.

9. Waitzkin H (2021) Confronting upstream causes of COVID-19 and other epidemics to follow. Int J Health Serv 51(1): 55-58

10. Frutos R, ML Roig, J Serra-Cobo, CA Devaux (2020) COVID-19: the conjunction of events leading to the coronavirus pandemic and lessons to learn for future threats. Frontiers in Medicine 7 (Article 223) doi: 10.3389/fmed.2020.00223.

11. Holloway L (2020) COVID-19 and a shifted perspective on infectious farm animal disease research. Agric Human Values 12:1-2. 